\title{
On the Development of the Chinese Character "Li" from the Perspective of Form Changes
}

\author{
Tianjin $\mathrm{Cao}^{1, *}$ \\ ${ }^{1}$ School of Cao Tianjin, Anyang Normal University, Anyang City, Henan Province, China \\ *Corresponding author. Email: 190107007@stu.aynu.edu.cn
}

\begin{abstract}
The Chinese character 'Li' (Rite) has its own development and connotations. In order to explore the connotations of "Li", it is practical to begin with the origin of the character "Li". This paper focuses on the evolution of "Li" and explores the changes in its form. The development of its form is explored by looking up relevant texts and conducting a counterpoint analysis." The character "Li" has evolved from the former oracle bone script to the small seal script to the traditional form to the present "Li", and a series of changes reflect the profound connotation of the character "Li".
\end{abstract}

Keywords: Chinese characters, Letter "Li", Chinese Character development.

\section{INTRODUCTION}

It is well known that China has been a nation of etiquette since ancient times, with great emphasis on the norms of etiquette. In China, the more typical weddings and funerals have a strict legal system of rituals and legal norms. There are different variations on the development of the word 'ritual' in terms of its form and meaning.

Most researches have focused on exploring the origin of "Li" (Rite). The origins of "Li" have been analysed through texts such as the analects, some scholars have also analysed its literal and philosophical connotations through the analects; more scholars have searched for the origins of rites through the role of legal culture in their formation. Although these studies explain the origins of the Rites, they fail to explain "Li" from the perspective of historical development. An analysis of the transformation of "Li" through time is therefore an innovative starting point for research. This paper will take the evolution of the word "Li" (Rite) through history as the main line of enquiry, analysing its transformation through different historical periods and examining the changes in its form in relation to information about its context.

This study will be divided into a total of three parts, each of which will be analysed following the pattern of development over time, ultimately exploring the origins and development of the word "Li" and the core elements of each historical stage. At the time of Confucius, when society was in chaos and war was frequent, Confucius advocated the restoration of the "Zhou Li" in order to regulate people's behaviour and thus stabilise social order. In the earlier Shang dynasty, there were strict rules of etiquette and law governing some important things in China, such as the 'nine ding', the status symbol of the royal nobility at the time. One and three tripods, five dafu, seven princes, and the Son of Heaven could be nine. [1] "Li" at that time referred to the relevant regulations and norms of etiquette. As the times progressed, the word "Li" (Rite) continued to change, with the Jin script becoming more simplified and dominated by the small seal script, with the shape gradually incorporating 'characters', to the point where at present, 'Li' sometimes refers to 'gifts', and sometimes to our everyday norms of behaviour, such as 'etiquette'.

\section{THE DEVELOPMENT OF THE LETTER "LI"}

The origin of rites can be dated back to ancient times. It is a good choice to explore the shape of the letter "Li" from the earliest writings discovered in China, which is system writing.

\subsection{The Origin of The Letter "Li" In Oracle Bone Inscriptions}

Oracle research has achieved some achievements in China. People have studied some of the meanings, but some Oracle are still unknown, which is still an unknown symbol, but the letter " Li"(Rite) can be found. 
By looking at the Oracle Dictionary, we can see that the letter "Li"(rite) in Oracle is very similar to the letter "Fung", but the "Li" in Oracle is more similar to a symbol, and the lines in Oracle have more curves. At that time, "ritual" was interchangeable with the letter "Fung", "Li" is the correct script, "Fung" was the first word, all read "Li(rite)". [2] The difference between those changed gradually over time.

The letter "Li" in Oracle, is an upper and lower structure font. The upper half of the font is divided into a hill with two "Fung". Different scholars give different explanations for the upper half of the letter "Li" in Oracle.

Some scholars believe that the upper half is divided into two jade series, which are closely related to jade. And the letter "Li" was the same word as "Fung", which refers to "jade". For example, according to $\mathrm{Mr}$. Wu Shuchen, this jade is "jade cong", namely the jade Banzi, which is an auxiliary tool used in archery. This "Cong" is a kind of Swiss jade, which was defined by Mr. Xia Nai. [3] It is a kind of jade with central round holes and peripheral circles.[4] On this basis, the origin of "Li" is further discussed.

On the other hand, some scholars believe that the upper half is grain. For example, Mr. Cai Feng comprehensively analyzed the early shape of the letter "Fung ", and concluded that the upper half of "Fung" was grain. [5] "Since I talk about the content on 'beans' is grain (grass) or jade. I have found many different methods of oracle bone inscriptions numbered J12148J12156, among which the word" Li(Rite)" numbered J12155 is like the shape of a container named "beans" is filled with grain'. And other oracle bone inscriptions 'Feng' are more like the shape of grain on 'beans'. The top part of the feng character should be grain, not jade series." [6]

Based on the above analysis, the top half of "Feng" should be more closely related to the grain. According to the Gong Yangzhuan and the notes by Hexiu " millet said ZiFan, in Yi Yue Sheng." Grain and the meat in" beans " are an indispensable sacrifice in ancient sacrifices. It can be seen that the upper part of the rich word should be a grain, rather than jade series.

As Mr. Wang Guowei said in his book, "Fung, like two jade in the shape of the vessel, and the ancient people salute jade".

To sum up, the top part of "Fung" is grain, and the top part of "Fung" is divided into jade.

We can look at these two letters in the picture below.

The lower half of "Fung" is "beans", a container, to serve meat.

When it comes to the offerings, we can briefly talk about the "Wuzhu culture". According to Mr.Wu Shuchen, the origin of the letter "Li" was related to Mao dance at that time, that is, combat dance. Engels once said in "Family, Private ownership and the Origin of Country" about the relationship between primitive human sacrifice and dance: dance, especially the main component of all religious ceremonies. [7] Related to dancing in sacrifice, $\mathrm{Mr}$.Wu Shuchen said, in ancient Chinese society, the connection between ritual and dance, is the dance of begging god to bless, to get the harvest of rich. These gains were put in the "beans", singing and dance to thank the gods. In the source of the word "ritual", we can see the close relationship between victorious worship and the dance, which can be said to be closely related to sacrifice.

\subsection{The Development Of The Letter "Li" -Jin Wen}

Jinwen generally refers to the words engraved on some bronze ware, with different transcripts on the curved surface of the vessels, which were exquisitely made and mostly in the hands of the nobles.

Since China had entered the Bronze Age in the Xia Dynasty, the bronze manufacturing and smelting were very exquisite. In the Zhou Dynasty, copper also named "gold", so the exquisite words on these bronzes were also known as "Jin Wen".

In Jin Wen, the shape of "Li" also evolved further.

"Letter Li(Rite) from drum" theory, the drum beginning is a diet device rather than a musical instrument. [8]

At this time, the letter "Li" was part on the basis of the oracle bone shape, the letter still an upper and lower font. The upper half is divided into "song", so as to put the lower half into "beans". However, the image of the "drum" in the last gradually disappeared. At that time, the letter was mainly related to the sacrifice.

To the Western Zhou Dynasty, the very clear "Fung" character used in the oracle bones of the Yin ruins seems to have been mixed with another letter. The real reason is ultimately due to the greater use of "Fung" characters in Jinwen. And the two "Fung" are different characters, but in Jin Wen, the two letters are no difference in the lower part of the word as beans. The beans all show the important related role of ritual vessels in the original sacrificial etiquette. [9]

At that time, there was also "Li" (Sweet wine), which is a letter mixed with the word "Li" on right and the letter "You"(Wine)on left, showing respect to god with beautiful jade and wine.

\subsection{The Traditional Character Of "Li" -Small Seal Script}

Small seal script is a popular kind of text in the Qin Dynasty, its shape is always complicated. 
There were many famous inscriptions at that time. Such as Mount Taishan carved stone, Langya carved stone and so on.

At that moment, there was another series of changes in the shape of "Li"(Rite). In the case of great unity, Chinese characters underwent a series of reforms and unification. The letter "Li" also added a radical at this time: show.

In Shuo Wen Jie Zi, Xu Shen, from the Eastern Han Dynasty, also gave a narrate of the letter "Li"(Rite), "Li" (Rite), is $\operatorname{lv}($ Shoe), which is a performance to sever the God and blessing "Lv, translated as perform. The "Li" at this time is mostly expressed as a ritual of divine blessing. The presentation is a post-added symbol.

Qing Dynasty Duan Yucai noted: from the Shi(Show), from the Fung(abundant), and read like Fung. There are five classics in the "Li ". However, these five classics are not as important as sacrifice. Therefore, the letter "Li" from the "Shi"(show). Fung is a utensil to show rites. Feng is the sound. It is also indicating that the rites are mostly related to sacrifice. The five classics of the paragraph refer to the five rites of Jili, fierce ceremony, concierge, military ceremony and Jiali.

At the same time, we can talk about the ancient "five rites", to further from the letter "Li" into the word "gift"." Five Rites" is the general name of the ancient Han nationality etiquette. To sacrifice as the auspicious ceremony, funeral as the fierce ceremony, military as the military ceremony, guests as the guests, crown wedding as Jiali, collectively known as the five rites. This "five rites" is the one sometimes used by the nobility. Among them, Jili is also the first of the five rites. [11] auspicious ritual is mainly the ritual of heaven, gods, earth and ghosts. Now we have learned and learned a lot is the Han $\mathrm{Li}$, as well as the more popular wearing Hanfu.

We can see from the beginning of the "five rites" that people attached great importance to ritual and sacrifice. Of course, at that time had a certain perfection, people's appearance, and sitting had a certain standard. After that, the basic shape of "Li" did not change much, but with the development of different fonts, the strokes were performed differently. The interframe structure of the font has not changed much in ancient times, as we now call traditional Chinese characters. The word "ritual" has developed different brush strokes in different times, and its connotation has changed in different dynasties. The idea of divine instruction gradually strengthened in the later period of autocratic rule, and rites also developed and changed step by step.

Explore the development and evolution of "Li", explore the shape of "Li", the origin of "Li", these exist in history, we need to open the history of clouds, looking for some traces, follow the clues, to find, to find. Know the history, live in the present, explore the future. As "Rite originated from the sacrificial rite", we searched for the influence of sacrificial totem on rite and sacrificial dance, such as the dance of praying for rain, as well as the influence of music on dance. Some people believe that the lower part of rite is a drum to appease the god. Another example is dance, the mysterious relationship between words, dance and ritual. These series of explorations reveal the veil of history layer by layer, and make the half-covered history reappear before people's eyes.

\subsection{Today's Letter "Li"(Rite)}

After the founding of the People's Republic of China, after a series of reforms, the finally established Chinese character simplification scheme has had a great impact on the Chinese characters that we currently use. The glyph of the simplified protocol gift was finally established based on some simplified words written by the ancient people, coupled with some other changes. Many of the simplified characters were written by Wang Xizhi, such as Dong, Long, Le.

At this time, the gift of the words also made a series of changes, the right complex upper "song" under the "beans" changed to " Vertical hook". This was simplified by the cursive script in the Sui Dynasty. And its shape in the ancient Shangshu, ancient filial piety scriptures have appeared. The shape retains the "symbol" on the left, and the right looks like a person bowing and bowing.

Not only has the appearance of "ritual" changed, but also its significance has changed a lot. Ancient Chinese is mainly monosyllabic, while modern Chinese is mainly monosyllabic words. Therefore, to understand the modern "ritual" word, we can use the way of group words, such as gifts, etiquette, etiquette and so on. It can be found that the change of its significance was previously mostly related to sacrifice, but now into ordinary people, its significance also further refers to people's daily norms of behavior.

We can see the simplification of today's "ritual" and "traditional rites", with simplified strokes of 5 paintings and traditional strokes of 17 strokes. It can largely improve people's writing efficiency. This can also reflect a change of minds. Since the founding of the People's Republic of China, the original three taps and nine worship gradually faded out of people's vision, the ceremony of Kings and ministers gradually disappeared, and become a handshake ceremony when people met. Some of people's daily norms, etiquette and the respect of others still exist in the word "ritual".

The analysis takes marriage as an example. Now there is still respectful tea in China, newlyweds want their parents to respect tea, pick up relatives in the morning, will send red envelopes and so on. This is related to the previous "ceremony", the previous wedding will be more complicated, there will be embroidered quilt wedding 
cover and other things, but these rituals do not bind people, more add a sense of ceremony.

There are red envelopes in China, and so on, which is more a kind of etiquette, a kind of heart, a blessin. Just like people used to put the coins in the dumplings, those who eat the dumplings with the coins will have good luck in the next year. To today, the "ritual" pays more attention to people's inner communication and communication. As the saying goes, "courtesy is light and affection".

Now the development and simplification of the word "ritual" and the change of its connotation also reflect the process of modernization and become more "modernization".

At present, China's "Confucius Institutes" have spread to all parts of the world, showing the traditional Chinese culture to people, but also letting more people know the wisdom of ancient Chinese people and people's way of life at that time. Chinese characters have also been introduced to the world, and you can also see calligraphy written by students in Confucius Institutes. And Confucius thought has benevolence, righteousness, propriety, wisdom and faith these big aspects, among which the word "propriety" is one of the five concepts, how a "propriety" word.

"Li" is People's Daily norms, People's Daily behavior etiquette of a benchmark, know li, understand li can make us more comfortable in daily life, more comfortable. In modern society, with the development of The Times, the relationship between people is closer, knowing etiquette can make us get along with others better. For example, smile and say hello to your friends when you meet them in the morning, thank them politely when they help you, and help others warmly when they ask for help. Fill your heart with sunshine, every day will be beautiful, and be polite to all of them. "Li" has a big culture. We can see the development of the letter "Li(Rite)" in the following picture.

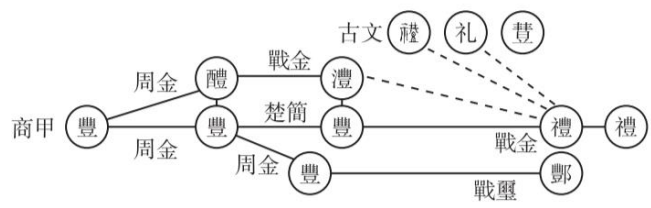

Figure 1 (Zhang Tiangong, An examination of "Feng" (Li) -- Taking the "Feng" (Li) of Shuo Wen Jie Zi as the main line)

\section{CONCLUSION}

In the development and evolution of the ritual characters, one can notice a lineage of the development of Chinese characters, from the original oracle bone script to the gold script engraved on bronze, to the small seal script and traditional characters engraved on stone slabs, to the simplified "Li" we write today. Character forms have evolved, from the ornaments closely associated with rituals to the disappearance of some of the imagery in the gold texts, to the inclusion of the small seal script, including the tendency to standardise and simplify characters. At first, "Li" is also used as ritual norms for sacrifices to serve the gods and send blessings and pray for blessings, and then the meaning gradually has changed to serve as a measure of communication between people. You can also see people moving from a state of worship of nature to a state of peaceful coexistence with nature, from primitive to scientific.

\section{REFERENCES}

[1] Li Xueqin, et al.The Spring and Autumn Ram infusion is sparse (punctuation book) [M].Beijing: Peking University Press, 1999

[2] Zhang Tianbow.Text "form" test [J].Yangtze River Review on Literature and Art, 2020, Issue 1:60-65

[3] Wu Shuchen.Looking for the original ritual investigation of French culture of ritual word formation process [D].Beijing: Peking University, 2010

[4] Zhang Huaqing, Hou Xiaoli.The distinction between - and rites and the relationship between Toyo and Feng [J].Folklore Studies, 2019, No

[5] Cai Feng, simple talk about "Feng", "Feng" two words [J].Northern literature.2014, No.1

[6] Xia Nai.Classification, designation, and use of Shang Dynasty jade articles [J].Archaeology, 1983, (5).

[7] Friedrich Engels.Family private ownership and National Origin $[\mathrm{M}]$ Marx and Engels anthology.Beijing: People's Publishing House, 1972

[8] Lei Hanqing."Li" word Original micro probe [J].Northwestern Division University Journal, 1995

[9] Wu Wanzhou.Ancient "courtesy" word new theory [D].The Graduate School of the Chinese Academy of Social Sciences

[10] Zhao Cui.The meaning change and cultural interpretation of the word "ritual" [D].Shandong: Qufu Normal University, 2010

[11] Cong Wang.Ancient "Five Rites" [J].Teachers Expo, 2000, Issue 8,39 